\title{
Explorations of Unilateral Diaphragmatic Paralysis
}

\author{
Alexandre Quesnel, ${ }^{1}$ Françoise Beuret Blanquart, ${ }^{2}$ Jean Paul Marie, ${ }^{3,4}$ and Eric Verin ${ }^{1,2,4}$ \\ ${ }^{1}$ Physiology Department, Rouen University Hospital, Rouen, France \\ ${ }^{2}$ CRMPR-HN les herbiers, 76420 Bois Guillaume, France \\ ${ }^{3}$ Cervicofacial Surgery Department, Rouen University Hospital, Rouen, France \\ ${ }^{4}$ Research Group on Ventilatory Handicap, GRHV, EA 3830, Rouen University, France \\ Correspondence should be addressed to Eric Verin; eric.verin@ugecam-normandie.fr
}

Received 19 May 2013; Revised 2 February 2014; Accepted 10 February 2014; Published 1 April 2014

Academic Editor: Norman R. Morris

Copyright (C) 2014 Alexandre Quesnel et al. This is an open access article distributed under the Creative Commons Attribution License, which permits unrestricted use, distribution, and reproduction in any medium, provided the original work is properly cited.

\begin{abstract}
Objective. The aim of the present study was to evaluate sniff test, maximal inspiratory pressure, and presence of paradoxical inspiratory diaphragmatic movements and their diagnostic value in patients referred for suspicion of diaphragmatic dysfunction. Methods. Twenty-two patients ( 8 men and 14 women, $58 \pm 13$ years) with suspected diaphragmatic dysfunction were included. Pulmonary function test was evaluated by spirometry. Diaphragm dysfunction was diagnosed with unilateral phrenic nerve stimulation. Esophageal pressure was recorded during sniff test and maximal static inspiratory movements. Detection of paradoxical diaphragmatic movement was performed with anteroposterior projection of chest X-ray fluoroscopic video. Results. Phrenic nerve stimulation enabled diagnosis of diaphragmatic paralysis in 15 of the 22 patients. The remaining 7 patients had normal explorations. Lung volumes were significantly lower in patients with diaphragmatic paralysis than in control subjects, as maximal inspiratory pressure. No patient with normal diaphragmatic exploration had paradoxical inspiratory movement. The combined diagnostic value of reduced esophageal pressure during sniff test, reduced esophageal pressure during maximal static inspiratory movements, and presence of paradoxical inspiratory movement had a sensitivity of $87 \%$ and a specificity of $71 \%$. Conclusion. Our results suggest that, in most cases, a combination of sniff test, maximal inspiratory pressure, and paradoxical inspiratory movement could help to diagnose diaphragmatic dysfunction. Nevertheless, phrenic nerve stimulation remains the best test for assessing diaphragmatic dysfunction.
\end{abstract}

\section{Introduction}

Diaphragmatic paralysis is common and may be due to infectious, iatrogenic, or malignant causes, although the most common is frigore paralysis. Damage to the diaphragm or the phrenic nerve decreases inspiratory pressure, leading to diaphragmatic weakness and reduction in inspiratory muscle capacity [1] and lung volume, which in turn impair respiratory muscle endurance [2] and produce dyspnea [3]. Diaphragmatic dysfunction should thus be considered as a differential diagnosis of unexplained dyspnea, but its definitive diagnosis is difficult to assert. Definitive diagnosis can be obtained by phrenic nerve stimulation combined with measurement of twitch transdiaphragmatic pressure $[4,5]$, but the technique may be difficult in some patients. In clinical practice, suspicion of diaphragmatic paralysis is usually based on diaphragmatic curse during diaphragmatic fluoroscopic examination [6], inspiratory muscle strength evaluated by sniff test and maximal inspiratory pressure, and phrenic nerve stimulation [7]. Nevertheless, the relative value of the different explorations, as well as their place in the diagnosis of diaphragmatic paralysis, has not yet been clearly established. Therefore, the aim of the present study was to evaluate their diagnostic value in patients with diaphragmatic paralysis diagnosed by phrenic nerve stimulation.

\section{Methods}

2.1. Patients. Twenty-two patients with suspicion of diaphragmatic dysfunction ( 8 men and 14 women, $58 \pm 13$ years) were retrospectively included in the study, from 2008 to 2012. Criteria for inclusion were suspicion of diaphragmatic 
dysfunction due to phrenic nerve paralysis. The patients did not suffer from other muscular or neurologic disorders and had no contraindication to undergoing magnetic stimulation.

2.2. Measurements. Lung volume, spirometry, and flow-volume curves were measured according to standard guidelines and expressed as percentages of published values [8] (MasterScreen Body Plethysmograph, Carefusion, San Diego, CA).

After insertion of an esophageal balloon catheter and a gastric balloon catheter $(70 \mathrm{~cm}$ long catheter; $1.4 \mathrm{~mm}$ external diameter; Marquat, Boissy Saint Léger, France), esophageal and gastric pressures [9] were measured in $\mathrm{cmH}_{2} \mathrm{O}$ with differential pressure transducer (DA 100C, Biopac Systems Inc., Santa Barbara, CA) [10]. Sniff maneuvers were performed at end of expiration with the patient in seated position. Patients were asked to perform sharp and maximal sniff maneuvers until peak esophageal pressure no longer increased. Maneuvers were only retained if sniff inspiratory time was under 0.5 seconds. Maximum sniff efforts were encouraged verbally and patients performed three series of five to ten sniffs, separated by at least 30 seconds [10]. Maximal static inspiratory pressure was measured from functional residual capacity (FRC) while seated and wearing a nose clip. Maximum inspiratory efforts were also encouraged verbally. Three maneuvers were performed separated by at least 30-second rest and continued until no further increase in pressure could be obtained [11].

Sniff test was considered as pathological if under $70 \mathrm{cmH}_{2} \mathrm{O}$ for men and $60 \mathrm{cmH}_{2} \mathrm{O}$ for women [11-13]. Maximal static inspiratory pressure (MIF) was measured from FRC while seated and wearing a nose clip [14]. MIF was considered as pathological if under $80 \mathrm{cmH}_{2} \mathrm{O}$ for men and $70 \mathrm{cmH}_{2} \mathrm{O}$ for women [11, 13-15]. Sniff maneuvers and maximal inspiratory pressure were performed before phrenic nerve stimulations with a 10-minute delay to avoid potentiation [16]. Diaphragm stimulations were performed using magnetic stimulation as previously described [17]. Briefly, bilateral phrenic nerve magnetic stimulations were performed at end expiratory time using a Magstim 200 stimulator powering a $90 \mathrm{~mm}$ circular coil (2.5 Tesla maximal output) (Magstim Ltd., Whitland, UK). The coil was placed at C7 level and three supramaximal reproducible stimulations were retained. Unilateral magnetic phrenic nerve stimulations (right and left phrenic nerve stimulations) were performed with a $43 \mathrm{~mm}$ branding iron type figure eight coil (Magstim Ltd., Whitland, UK), according to the technique described by Mills et al. [18]. A diagnosis of unilateral diaphragmatic paralysis was defined as a decrease of under $10 \mathrm{cmH}_{2} \mathrm{O}$ in transdiaphragmatic pressure (Pdi) in response to unilateral phrenic nerve stimulation (ums) [13].

Anteroposterior projection fluoroscopic images were acquired with a radio amplifier (Flexiview 8800, General Electric, United Medical Technologies Corp., Fort Myers, FL) and recorded on a computer at 12 frames per second for later analysis (MMS, Tubingen, The Netherlands). Two sequences were recorded for each hemidiaphragm and two sequences were performed with the entire diaphragm in the field. The patients were in an upright position during testing and were asked to perform sharp and strong sniffs as previously learned during sniff test. A paradoxical inspiratory movement was defined as an inspiratory elevation of one hemidiaphragm during normal movement of the other hemidiaphragm, that is, a descent during the sharp sniff [19].

2.3. Data Analysis. Esophageal pressure amplitudes were measured from baseline to peak. Maximal sniff esophageal pressures (Pes, sniff) and maximal static inspiratory pressure (Pes, mip) were retained for analysis. Maximal esophageal and gastric pressures induced by phrenic nerve cervical magnetic stimulation were measured to calculate transdiaphragmatic pressure (Pdi) during cervical magnetic stimulation (CMS) or unilateral cervical stimulation (UMS) (resp., Pdi, cms and Pdi, ums). Presence or absence of paradoxical diaphragmatic inspiratory movements was noted.

2.4. Statistics. Statistical analyses were performed using StatView 5.0 software (SAS Institute Inc.). All results are expressed as means \pm standard error (SE). Differences between the two groups of patients were analyzed with nonparametric Mann-Whitney test and were considered significant when the probability $P$ of a type I error was 0.05 or less. Sensitivity and specificity were calculated for each test, with diaphragmatic dysfunction being defined by a pathological Pdi measurement in response to unilateral phrenic nerve stimulation.

\section{Results}

The results of transdiaphragmatic pressure (Pdi) measurement in response to unilateral phrenic nerve stimulation enabled diagnosis of 15 diaphragmatic paralyses and 7 normal explorations. Ten of the 15 diaphragmatic paralyses had right diaphragmatic dysfunction and five had left diaphragmatic dysfunction. Vital capacity (VC), forced expiratory volume in one second (FEV1), FRC, Pes, mip, Pes, sniff, Pdi, ums, Pdi, $\mathrm{cms}$, and videofluoroscopy results are summarized in Table 1.

3.1. Pulmonary Function Tests. Results are presented in Table 1. There was a significant difference between the two groups for FEV1 $(P=0.01)$ and VC $(P=0.05)$. FRC tended to be lower in patients with diaphragmatic paralysis, but difference was not statistically significant $(P=0.1)$.

3.2. Diaphragmatic Strength. Pes, sniff was not statistically lower in patients with diaphragmatic paralysis (resp., $82.1 \pm$ $6.8 \mathrm{cmH}_{2} \mathrm{O}$ versus $\left.69 \pm 4.9 \mathrm{cmH}_{2} \mathrm{O}, P=0.08\right)$. Pes, mip and Pdi, cms were higher in patients with no diaphragmatic paralysis than in patients with diaphragmatic paralysis (resp., $84.0 \pm 9.5 \mathrm{cmH}_{2} \mathrm{O}$ versus $66.1 \pm 4.3 \mathrm{cmH}_{2} \mathrm{O}, P<0.05$, and 28.1 $\pm 2.4 \mathrm{cmH}_{2} \mathrm{O}$ versus $13.1 \pm 1,5 \mathrm{cmH}_{2} \mathrm{O}, P<0.0001$ (Figure 1)). Two patients did not correctly perform the maneuver to obtain maximal inspiratory pressure. Pdi, ums was not different between right and left side in patients with normal explorations (right: $16.4 \pm 1.5 \mathrm{cmH}_{2} \mathrm{O}$, left: $18.2 \pm 1.4 \mathrm{cmH}_{2} \mathrm{O}$, $P=0.11)$. Pdi, ums was significantly lower in patients with diaphragmatic paralysis, for both sides (Figure 2). Sensitivity 


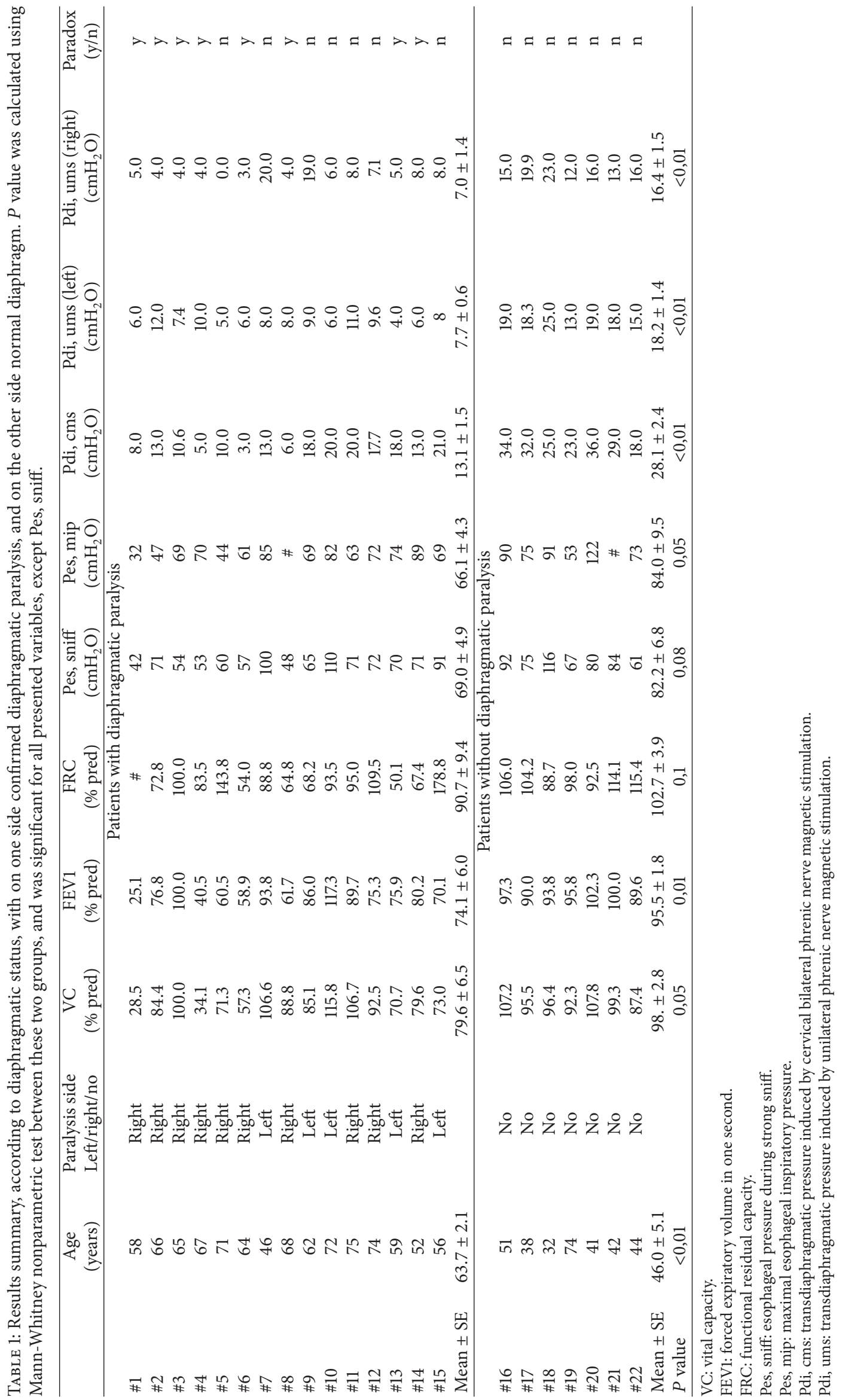




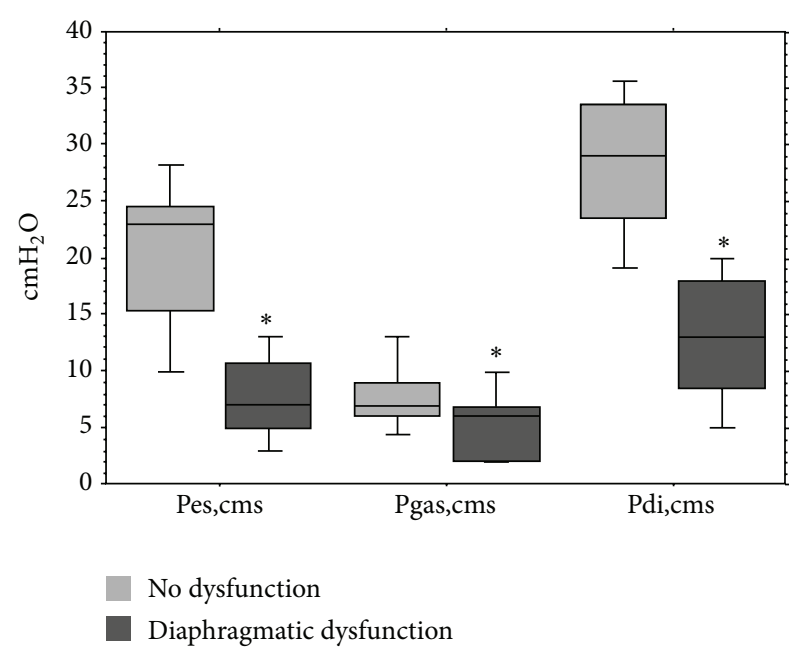

FIGURE 1: Esophageal pressure, gastric pressure, and transdiaphragmatic pressure induced by cervical bilateral phrenic nerve magnetic stimulation (Pes, cms, Pgas, cms, and Pdi, cms). Distribution of values between patients with normal diaphragmatic explorations and patients with diaphragmatic paralysis, expressed in $\mathrm{cmH}_{2} \mathrm{O}$. Asterisk denotes significant difference $(P<0.05)$.

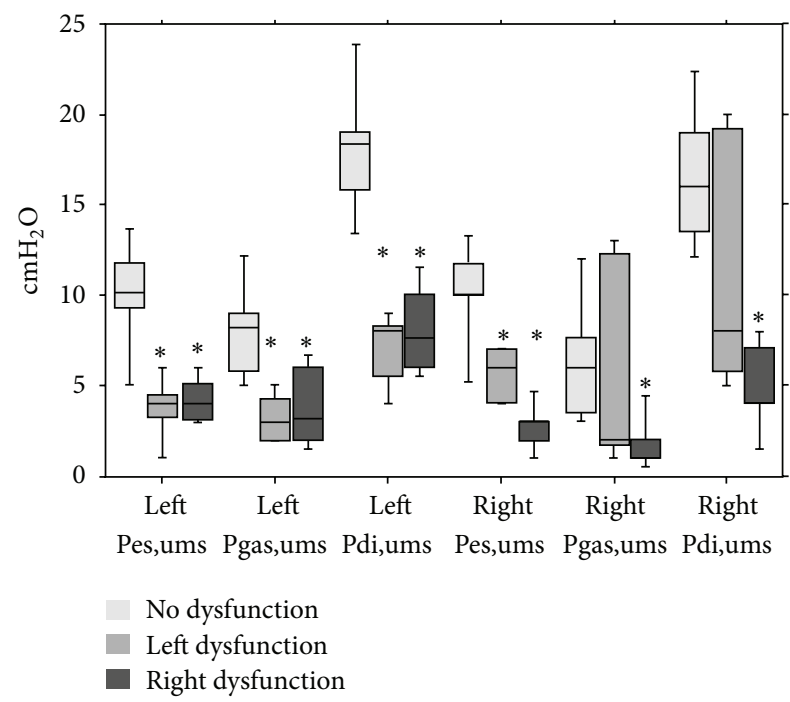

FIGURE 2: Esophageal pressure, gastric pressure, and transdiaphragmatic pressure induced by unilateral phrenic nerve magnetic stimulation (Pes, ums, Pgas, ums, and Pdi, ums). Distribution of values for each side, between patients with normal diaphragmatic explorations and patients with diaphragmatic paralysis, expressed in $\mathrm{cmH}_{2} \mathrm{O}$. For patients with diaphragmatic dysfunction, results are divided according to the side of the injury. Asterisk denotes significant difference with normal patients $(P<0.05)$.

and specificity were, respectively, $53 \%$ and $100 \%$ for Pes, sniff, $67 \%$ and $71 \%$ for Pes, mip, and $93 \%$ and $86 \%$ for Pdi, cms.

3.3. Diaphragmatic Movements. On diaphragm radioscopy, no patient with normal diaphragmatic exploration had paradoxical inspiratory movement. In patients with diaphragmatic paralysis, eight experienced paradoxical inspiratory movement and seven normal diaphragmatic curse for the paralyzed hemidiaphragm. Sensitivity was therefore $53 \%$ and specificity $100 \%$.

When Pes, sniff was abnormal, Pes, mip was abnormal and presence of a paradoxical inspiratory movement was noted; sensitivity was calculated at $87 \%$ and specificity at $71 \%$ for diaphragmatic dysfunction diagnosis.

\section{Discussion}

This study demonstrated that diaphragmatic paralysis induced respiratory muscle weakness and paradoxical inspiratory movements of the paralyzed hemidiaphragm in a majority of patients with good sensitivity. Nevertheless, phrenic nerve stimulation remains the gold standard method for diagnosis of diaphragmatic paralysis.

While numerous methods have been proposed for diagnosing diaphragmatic paralysis and diaphragmatic weakness, magnetic phrenic nerve stimulation [12], either unilateral [15] or bilateral $[20,21]$, is currently the most precise technique for diagnosing phrenic nerve paralysis $[2,12]$ or diaphragmatic weakness $[12,22]$. The major difficulty in diaphragmatic explorations is that there are no cut-off values for clear separation of "normal" and "pathological" explorations. Hart et al. proposed a Pdi, ums of less than $3.5 \mathrm{cmH}_{2} \mathrm{O}$ [2]. This cutoff was arbitrarily chosen, and the authors acknowledged that, with such a low value, only severe diaphragm weakness would be diagnosed as "diaphragm paralysis." Luo et al. investigated the value of Pdi, cms on normal subjects and found it to be $28 \pm 5 \mathrm{cmH}_{2} \mathrm{O}$ [23]. From this study, Steier et al. [24] proposed as cut-off value $18 \mathrm{cmH}_{2} \mathrm{O}$ for Pdi, cms, but did not mention Pdi, ums. Recently, a review [13], proposed a cut-off value of $10 \mathrm{cmH}_{2} \mathrm{O}$ for Pdi, ums and $20 \mathrm{cmH}_{2} \mathrm{O}$ for Pdi, cms to diagnose clinically significant diaphragmatic weakness, which we decided to take into account. Differences in diaphragmatic strengths obtained after bilateral phrenic nerve stimulation compared to unilateral phrenic nerve stimulation observed in our study have been previously described and can be explained by the stabilizing effect of cervical magnetic stimulations on the rib cage [25]. It should be noted that the relatively low number of patients included in the present study is due to the fact that inclusion criteria were difficult to achieve for many patients. In particular Pdi, $\mathrm{cms}$ and Pdi, ums were very often lacking, with patients not achieving test completion.

Our results confirm that mobilizable lung volumes are lower in cases of diaphragmatic dysfunction, in absence of any other pulmonary diseases. Consequently, pulmonary function tests are useful as a first approach and to ensure easily led follow-up of patients suffering from diaphragmatic dysfunction. Nevertheless, normal pulmonary function test is unable to rule out diaphragmatic dysfunction. In our study, Pes, sniff was the only test which allowed assessment of diaphragmatic dysfunction when abnormal with no false positive, but with subsequent false negatives [26]. It seems from the report that sniff transdiaphragmatic pressure can be higher than maximal static transdiaphragmatic pressure $[27,28]$, although conflicting results have been reported in controls [29] and in patients [30]. 
Diaphragmatic video fluoroscopy can provide dynamic information on diaphragmatic movement. A study performed on inspiratory-expiratory radiographs obtained from 350 subjects aged between 30 and 80 years, during quiet tidal breathing in an erect position, and without evidence of respiratory disease, found mean tidal excursions of the domes of the right and left hemidiaphragms to be 3.3 and $3.5 \mathrm{~cm}$, respectively [31]. Tidal diaphragmatic movement was on average $0.5 \mathrm{~cm}$ lower in women than in men. Despite similar mean values, unequal movement of the two hemidiaphragmatic domes in an individual subject is common, most commonly greater on the right $[32,33]$. Unilateral diaphragm paralysis is easier to detect because there is paradoxical motion during tidal inspiration, with ascent of the paralyzed dome, contrasting with descent of the normal hemidiaphragm; this contrast can be amplified by sniff test, which induces a vigorous, short contraction in the normal hemidiaphragm [34]. In our study, paradoxical motion, such as Pes, Sniff, has excellent specificity, but lower sensitivity. Its presence can enable assessment of the existence of diaphragmatic dysfunction, but this exploration can be proved wrong for moderate dysfunction of a hemidiaphragm, or on the contrary for severe bilateral paralysis.

As seen above, no one single exploration (Pes, sniff, Pes, mip, search for paradoxical motion during sniff manoeuvre) is relevant in the diagnosis of diaphragmatic dysfunction, due to numerous false negatives, except Pdi, ums or Pdi cms measurements. Nevertheless, combining Pes, sniff, Pes, mip and paradoxical motion allows obtention of high sensitivity, at $87 \%$. Consequently, a combination of easily performed, noninvasive explorations, confronted with clinical context, is very useful. Phrenic nerve stimulation should therefore be used for uncommon cases, when clinical argument is insufficient for diagnosis of diaphragmatic weakness, or when it is necessary to give the precise level of diaphragmatic paralysis.

In conclusion, our results suggest that, in most cases, combining Pes, sniff, Pes, mip measurements and diaphragmatic videofluoroscopy in search of an eventual paradoxical inspiratory diaphragmatic movement during sniff maneuvers is useful to manage suspicion of diaphragmatic dysfunction. However, phrenic nerve stimulation remains the best exploration to confirm diagnosis.

\section{Disclosure}

Neither funding nor grants nor equipment was provided for the project by any source; there was no financial profit for the authors. There has been no previous presentation of the research, paper, or abstract in any form.

\section{Conflict of Interests}

The authors declare that there is no conflict of interests.

\section{Acknowledgment}

The authors are grateful to Nikki Sabourin-Gibbs, Rouen University Hospital, for editing the paper.

\section{References}

[1] C. M. Laroche, A. K. Mier, J. Moxham, and M. Green, "Diaphragm strength in patients with recent hemidiaphragm paralysis," Thorax, vol. 43, no. 3, pp. 170-174, 1988.

[2] N. Hart, A. H. Nickol, D. Cramer et al., "Effect of severe isolated unilateral and bilateral diaphragm weakness on exercise performance," American Journal of Respiratory and Critical Care Medicine, vol. 165, no. 9, pp. 1265-1270, 2002.

[3] C. M. Laroche, N. Carroll, J. Moxham, and M. Green, "Clinical significance of severe isolated diaphragm weakness," American Review of Respiratory Disease, vol. 138, no. 4, pp. 862-866, 1988.

[4] M. Aubier, D. Murciano, Y. Lecocguic, N. Viires, and R. Pariente, "Bilateral phrenic stimulation: a simple technique to assess diaphragmatic fatigue in humans," Journal of Applied Physiology, vol. 58, no. 1, pp. 58-64, 1985.

[5] T. Similowsky, B. Fleury, S. Launois, H. P. Cathala, P. Bouche, and J.-P. Derenne, "Cervical magnetic stimulation (SMC). A new method of bilateral phrenic nerve stimulation usable in clinical practice," Revue des Maladies Respiratoires, vol. 5, no. 6, pp. 609-614, 1988.

[6] G. J. Gibson, "Diaphragmatic paresis: pathophysiology, clinical features, and investigation," Thorax, vol. 44, no. 11, pp. 960-970, 1989.

[7] E. Verin, J. Marie, C. Tardif, and P. Denis, "Spontaneous recovery of diaphragmatic strength in unilateral diaphragmatic paralysis," Respiratory Medicine, vol. 100, no. 11, pp. 1944-1951, 2006.

[8] P. H. Quanjer, G. J. Tammeling, J. E. Cotes, O. F. Pedersen, R. Peslin, and J. C. Yernault, "Lung volumes and forced ventilatory flows. Report Working Party Standardization of Lung Function Tests, European Community for Steel and Coal. Official Statement of the European Respiratory Society," The European Respiratory Journal. Supplement, vol. 16, pp. 5-40, 1993.

[9] A. Baydur, P. K. Behrakis, and W. A. Zin, "A simple method for assessing the validity of the esophageal balloon technique," American Review of Respiratory Disease, vol. 126, no. 5, pp. 788791, 1982.

[10] F. Héritier, F. Rahm, P. Pasche, and J. Fitting, "Sniff nasal inspiratory pressure: a noninvasive assessment of inspiratory muscle strength," American Journal of Respiratory and Critical Care Medicine, vol. 150, no. 6, part 1, pp. 1678-1683, 1994.

[11] N. Syabbalo, "Assessment of respiratory muscle function and strength," Postgraduate Medical Journal, vol. 74, no. 870, pp. 208-215, 1998.

[12] C. Uldry and J.-W. Fitting, "Maximal values of sniff nasal inspiratory pressure in healthy subjects," Thorax, vol. 50, no. 4, pp. 371-375, 1995.

[13] F. D. McCool and G. E. Tzelepis, "Dysfunction of the diaphragm," The New England Journal of Medicine, vol. 366, no. 10, pp. 932-942, 2012.

[14] L. F. Black and R. E. Hyatt, "Maximal respiratory pressures: normal values and relationship to age and sex," American Review of Respiratory Disease, vol. 99, no. 5, pp. 696-702, 1969.

[15] C. Bruschi, I. Cerveri, M. C. Zoia et al., "Reference values of maximal respiratory mouth pressures: a population-based study," American Review of Respiratory Disease, vol. 146, no. 3, pp. 790-793, 1992.

[16] "ATS/ERS Statement on respiratory Muscle Testing," American Journal of Respiratory and Critical Care Medicine, vol. 166, pp. 518-624, 2002. 
[17] T. Similowski, B. Fleury, S. Launois, H. P. Cathala, P. Bouche, and J. P. Derenne, "Cervical magnetic stimulation: a new painless method for bilateral phrenic nerve stimulation in conscious humans," Journal of Applied Physiology, vol. 67, no. 4, pp. 1311-1318, 1989.

[18] G. H. Mills, D. Kyroussis, C.-H. Hamnegard, S. Wragg, J. Moxham, and M. Green, "Unilateral magnetic stimulation of the phrenic nerve," Thorax, vol. 50, no. 11, pp. 1162-1172, 1995.

[19] M. J. Tobin, "Respiratory muscles in disease," Clinics in Chest Medicine, vol. 9, no. 2, pp. 263-286, 1988.

[20] G. H. Mills, D. Kyroussis, C. H. Hamnegard, M. I. Polkey, M. Green, and J. Moxham, "Bilateral magnetic stimulation of the phrenic nerves from an anterolateral approach," American Journal of Respiratory and Critical Care Medicine, vol. 154, no. 4, part 1, pp. 1099-1105, 1996.

[21] T. Similowski, C. Straus, V. Attali, A. Duguet, B. Jourdain, and J. Derenne, "Assessment of the motor pathway to the diaphragm using cortical and cervical magnetic stimulation in the decision-making process of phrenic pacing," Chest, vol. 110, no. 6, pp. 1551-1557, 1996.

[22] A. Teixeira, P. Cherin, A. Demoule et al., "Diaphragmatic dysfunction in patients with idiopathic inflammatory myopathies," Neuromuscular Disorders, vol. 15, no. 1, pp. 32-39, 2005.

[23] Y. M. Luo, N. Hart, N. Mustfa et al., "Reproducibility of twitch and sniff transdiaphragmatic pressures," Respiratory Physiology and Neurobiology, vol. 132, no. 3, pp. 301-306, 2002.

[24] J. Steier, S. Kaul, J. Seymour et al., "The value of multiple tests of respiratory muscle strength,” Thorax, vol. 44, pp. 990-996, 1989.

[25] T. Similowski, C. Straus, V. Attali, A. Duguet, and J. Derenne, "Cervical magnetic stimulation as a method to discriminate between diaphragm and rib cage muscle fatigue," Journal of Applied Physiology, vol. 84, no. 5, pp. 1692-1700, 1998.

[26] G. H. Mills, D. Kyroussis, C. Hamnegard et al., "Cervical magnetic stimulation of the phrenic nerves in bilateral diaphragm paralysis," American Journal of Respiratory and Critical Care Medicine, vol. 155, no. 5, pp. 1565-1569, 1997.

[27] J. M. Miller, J. Moxham, and M. Green, "The maximal sniff in the assessment of diaphragm function in man," Clinical Science, vol. 69, no. 1, pp. 91-96, 1985 .

[28] C. M. Laroche, A. K. Mier, J. Moxham, and M. Green, "The value of sniff esophageal pressures in the assessment of global inspiratory muscle strenght," American Review of Respiratory Disease, vol. 138, no. 3, pp. 598-603, 1988.

[29] Y. F. Heijdra, P. N. R. Dekhuijzen, C. L. A. van Herwaarden, and H. T. M. Folgering, "Differences between sniff mouth pressures and static maximal inspiratory mouth pressures," European Respiratory Journal, vol. 6, no. 4, pp. 541-546, 1993.

[30] F. Heritier, C. Perret, and J.-W. Fitting, "Maximal sniff mouth pressure compared with maximal inspiratory pressure in acute respiratory failure," Chest, vol. 100, no. 1, pp. 175-178, 1991.

[31] E. A. Lennon and G. Simon, "The height of the diaphragm in the chest radiograph of normal adults," British Journal of Radiology, vol. 38, no. 456, pp. 937-943, 1965.

[32] D. A. Young and G. Simon, "Certain movements measured on inspiration-expiration chest radiographs correlated with pulmonary function studies," Clinical Radiology, vol. 23, no. 1, pp. 37-41, 1972.

[33] I. Y. Ch'en and J. D. Armstrong II, "Value of fluoroscopy in patients with suspected bilateral hemidiaphragmatic paralysis," American Journal of Roentgenology, vol. 160, no. 1, pp. 29-31, 1993.
[34] J. G. Houston, M. Fleet, M. D. Cowan, and N. C. McMillan, "Comparison of ultrasound with fluoroscopy in the assessment of suspected hemidiaphragmatic movement abnormality," Clinical Radiology, vol. 50, no. 2, pp. 95-98, 1995. 


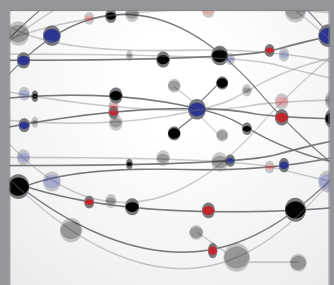

The Scientific World Journal
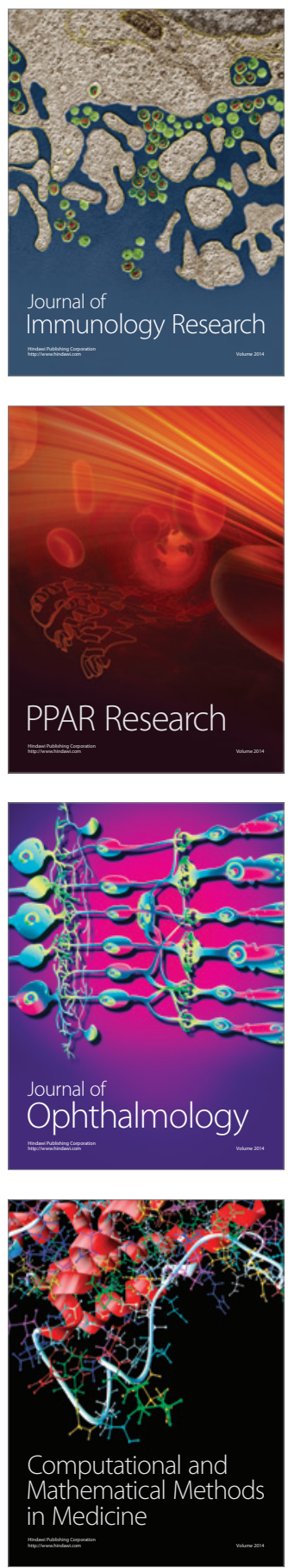

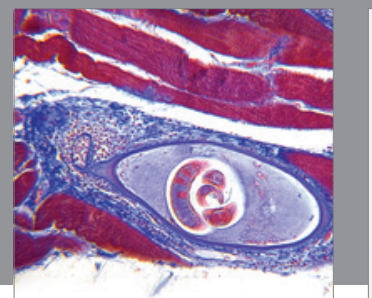

Gastroenterology

Research and Practice
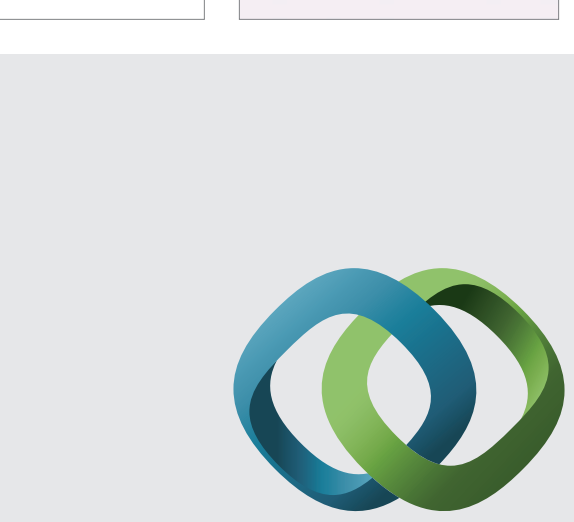

\section{Hindawi}

Submit your manuscripts at

http://www.hindawi.com
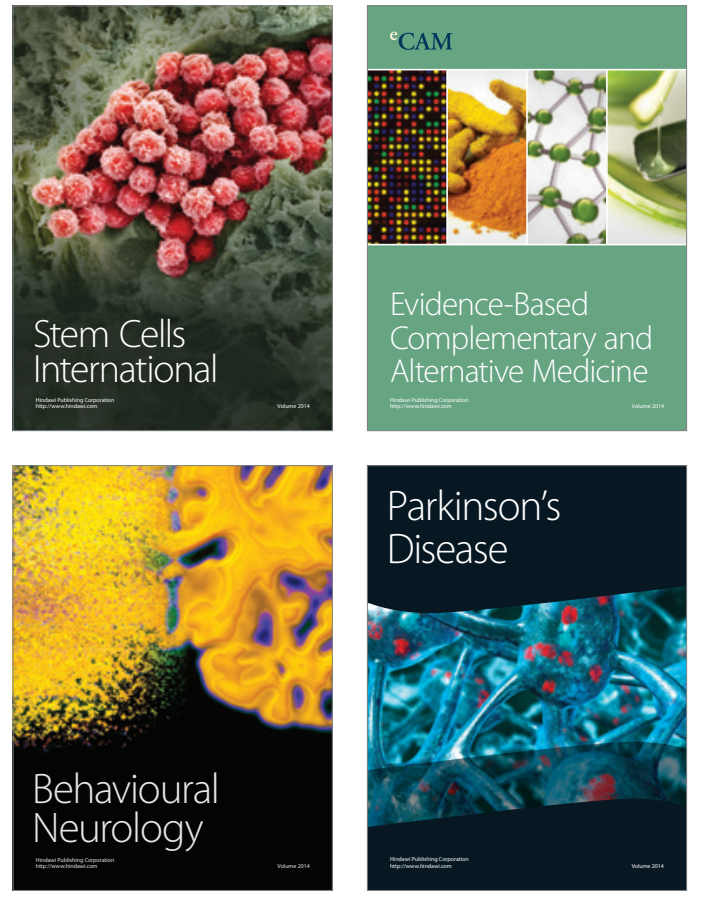
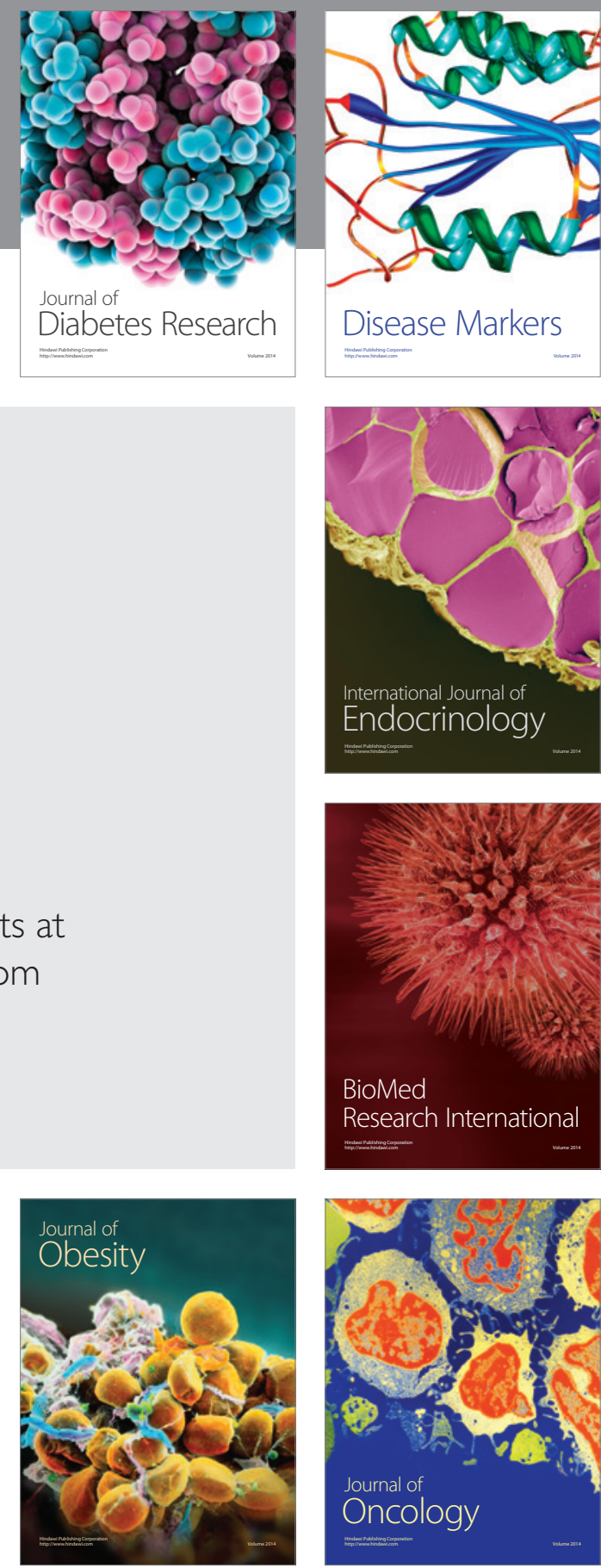

Disease Markers
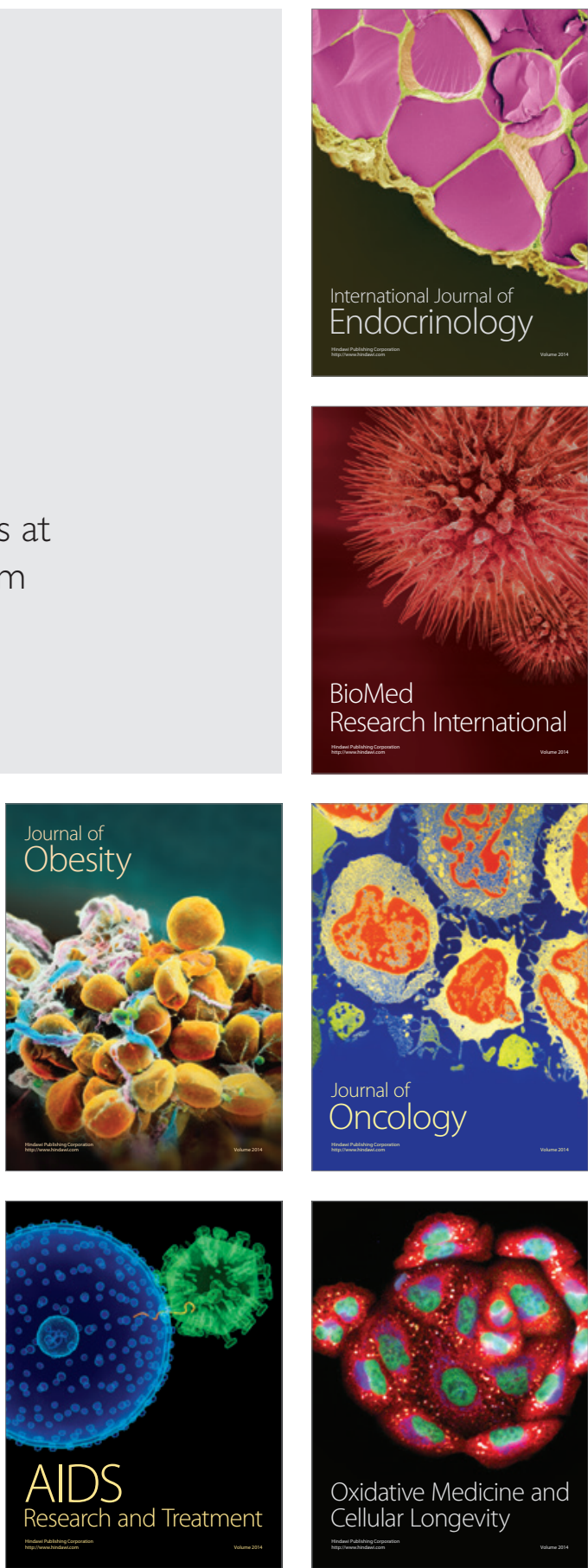